\title{
A Glutamate-Dopamine Interaction in the Persistent Enhanced Response to Amphetamine in Nucleus Accumbens Core but not Shell Following a Single Restraint Stress
}

\author{
Alejandra M Pacchioni' ${ }^{1,3}$, Martine Cador ${ }^{2}$, Claudia Bregonzio' and Liliana M Cancela*,' \\ 'Departamento de Farmacología, Facultad de Ciencias Químicas, Universidad Nacional de Córdoba, Córdoba, Argentina; ${ }^{2}$ Laboratoire de \\ Neuropsychobiologie des Désadaptations, CNRS-UMR554I, Université Victor Segalen, Bordeaux II, Bordeaux Cedex, France
}

\begin{abstract}
The administration of psychostimulant drugs or stress can elicit a sensitized response to the stimulating and reinforcing properties of the drug. We previously demonstrated that a single restraint stress session enhanced d-amphetamine (d-AMPH)-induced locomotion the day after the stress session, which lasted up to 8 days. The present experiments were designed to identify the contribution of major dopamine (DA) brain areas in the short- and long-lasting enhancement of d-AMPH-induced locomotion following a single stress, and to test the involvement of $\mathrm{N}$-methyl-D-aspartate (NMDA) receptors in that phenomena. To achieve our goal, $24 \mathrm{~h}$ and 8 days after a 2-h restraint stress session either with or without a NMDA receptor blockade, we measured locomotor activity and DA overflow in nucleus accumbens (NAcc) core and shell and caudate putamen (CPu) following a d-AMPH injection ( $0.5 \mathrm{mg} / \mathrm{kg}$ i.p.). The stimulant effect of $\mathrm{d}$-AMPH on DA overflow was enhanced in all nuclei at $24 \mathrm{~h}$ after a single stress, while at 8 days the enhanced responsiveness was maintained only in the NAcc core. When the rats were administered with MK-80I (0.I mg/kg i.p.) 30 min before restraint stress, the d-AMPH-induced enhancement on locomotor activity and DA neurotransmission was prevented in all studied brain areas at both times. These findings show that a glutamate-dopamine link is underlying the short- and long-term d-AMPH-induced enhancement on DA and locomotor activity following stress. The persistent glutamate-dependent DA enhancement in NAcc core highlights the relevance of this region in the long-term proactive effects of stress on vulnerability to drug abuse.

Neuropsychopharmacology (2007) 32, 682-692. doi:I0.1038/sj.npp. I30I080; published online 19 April 2006
\end{abstract}

Keywords: restraint stress; dopamine release; MK-80I; d-amphetamine; long-term effects; nucleus accumbens core and shell

\section{INTRODUCTION}

Clinical and epidemiological studies point out that stress is positively related to the use and abuse of addictive drugs (O'Doherty, 1991). In laboratory animals, there is evidence for the proactive influence of stress on the behavioral and neurochemical responses to many of abused drugs. It has been shown that exposure to different stressors induces a potentiation of the psychostimulant effects of both amphetamine (AMPH) and cocaine (see Lu et al, 2003). As well, their rewarding properties using the place preference (Capriles and Cancela, 1999) or the drug self-administration

*Correspondence: Dr LM Cancela, Departamento de Farmacología, Facultad de Ciencias Químicas, Universidad Nacional de Córdoba, Ciudad Universitaria, (5000) Córdoba, Córdoba, Argentina, Tel: +54 35। 4334437, Fax: + 54 35 | 4334420, E-mail: Icancela@fcq.unc.edu.ar ${ }^{3}$ Current address: Department of Neurosciences, Medical University of South Carolina, Charleston, SC, USA

Received 2 I June 2005; revised I March 2006; accepted 4 March 2006 Online publication: 13 March 2006 at http://www.acnp.org/citations/ Npp03 I 306050404/default.pdf paradigms (Piazza and LeMoal, 1998; Shaham et al, 2003) have been shown to be enhanced in previously stressed rats.

A preponderant role has been attributed to the dopaminergic mesocorticolimbic system in the rewarding and stimulating effects of drugs of abuse as well as in the response to stress. Both drugs of abuse and stress experiences increase dopamine (DA) release in mesocorticolimbic structures such as the nucleus accumbens (NAcc) core and shell and striatum (Imperato et al, 1993; Kalivas and Duffy, 1995; Pontieri et al, 1995). Besides an implication in the acute effect of stress and drugs, accumbens and striatal dopaminergic neurotransmission are thought to be involved in the development and expression of long-term locomotor sensitization as well as in relapse to drug seeking (Kalivas and Stewart, 1991; Robinson and Berridge, 2000; Vezina et al, 2002). Although behavioral effects and changes in DA are affected in parallel by stress and psychostimulants, a strict relationship between them is not clearly evidenced (see Di Chiara, 1995; Robinson et al, 1988; Paulson and Robinson, 1995; Pierce and Kalivas, 1997). In addition to DA, a common mechanism between stressand drug-induced long-term neuroadaptation might be the 
excitatory amino-acid neurotransmission, which has been shown to be involved in drug-induced neuroadaptations (Wolf, 1998; Cador et al, 1999). Consistently, we have shown that MK-801 blocked the restraint stress-induced sensitization of the locomotor psychostimulant effect of d-AMPH (Pacchioni et al, 2002) and morphine (Capriles et al, 2002). Furthermore, as an enhancement of the d-AMPH-induced striatal DA release seemed to underlie the locomotor sensitization following a single restraint stress (Pacchioni et $a l, 2002)$, it is highly probable that the influence of MK-801 could also be observed in the releasing effect of the drugs at DA terminals.

As locomotor sensitization to d-AMPH was observed at $24 \mathrm{~h}$ and 8 days following a single restraint stress (Diaz-Otañez et al, 1997), in the present study we looked into short and long-lasting presynaptic changes in the dopaminergic effects of d-AMPH in the dorsal striatum $(\mathrm{CPu})$ and the two subdivisions 'core' (NAcc core) and 'shell' (NAcc shell) of the NAcc. The NAcc is a heterogeneous structure that can be separated anatomically into core and shell subdivisions (Pennartz et al, 1994), where DA transmission is differentially sensitive to drugs of abuse and undergoes different habituation patterns to repeated treatment with drugs or stress (see Di Chiara et al, 2004). The effects of the drug on DA release were analyzed by microdialysis from these nuclei at $24 \mathrm{~h}$ and 8 days after a single restraint stress. The implication of a glutamatergic mechanism was further studied by MK-801 or saline being peripherally administered before the restraint stress.

\section{MATERIALS AND METHODS}

\section{Animals}

Adult male Wistar rats (250-330 g) purchased from Facultad de Ciencias Veterinarias (Universidad Nacional de La Plata, Buenos Aires, Argentina) were used. The rats were maintained at $20-24^{\circ} \mathrm{C}$ under a $12 \mathrm{~h}$ light-dark cycle (lights on at 0700 hours) with free access to food and water. Rats were placed in the colony room for at least 7 days before experimental tests and housed two individuals per cage during the experiment.

\section{Surgery}

Rats were anesthetized with chloral hydrate $(400 \mathrm{mg} / \mathrm{kg}$ i.p.) and placed in a Stoelting stereotaxic instrument with the incisor bar at $-3.3 \mathrm{~mm}$ above the interaural line. The skull was exposed and a hole was drilled to allow implantation of a CMA/12 microdialysis guide cannulae in NAcc core, NAcc shell and $\mathrm{CPu}$. The coordinates were (in $\mathrm{mm}$ ): for NAcc core $\mathrm{AP}+1.4, \mathrm{ML} \pm 1.5$ and $\mathrm{DV}-7.8$; for $\mathrm{NAcc}$ shell $\mathrm{AP}+1.4$, $\mathrm{ML} \pm 0.7$ and $\mathrm{DV}-8.0$; and, for $\mathrm{CPu} \mathrm{AP}+1.2, \mathrm{ML} \pm 2.5$ and DV-6.0. The cannulae were secured in place with two stainless steel screws and dental cement. The rats were allowed to recover for $48-72 \mathrm{~h}$.

\section{Drugs}

d-AMPH sulphate was purchased from Sigma Chemical Co. (St Louis, MO); and (+)-MK-801 hydrogen maleate from Research Biochemical International (Natick, MA). Drugs were dissolved in saline immediately before use. The doses were calculated on the basis of the weight of the salt of each drug, and were chosen considering our previous works (Diaz-Otañez et al, 1997; Pacchioni et al, 2002).

\section{Stress}

Rats were immobilized for $2 \mathrm{~h}$ in a Plexiglas restraining device. The Plexiglas cylinders were devised so that the rats' head and tail emerged from the front and the rear, respectively. The stress phase was conducted between 1000 hours and 1400 hours All procedures were handled in accordance with the NIH Guide for the Care and Use of Laboratory Animals as approved by Animal Care and Use Committee of the Facultad de Ciencias Químicas, Universidad Nacional de Córdoba, Argentina.

\section{Locomotor Activity}

The testing apparatus consisted of rectangular cages $(30.5 \times 19.5 \times 46.5 \mathrm{~cm})$ equipped with two parallel infrared photocell beams located $3 \mathrm{~cm}$ above the floor. Interruption of either beam resulted in a photocell count. The testing apparatus was placed in a different room from the one where restraint was applied to avoid any conditioning effects. All rats were tested once between 0900 hours and 1800 hours, under white light in a quiet room. They were placed individually in the testing apparatus for a 1-h habituation period, before being injected with d-AMPH $(0.5 \mathrm{mg} / \mathrm{kg}$ i.p. $)$, and motor activity counts were monitored at $10 \mathrm{~min}$ intervals for $2 \mathrm{~h}$ following the injection.

\section{Microdialysis Procedure}

In the morning of the experimental day, a CMA/12 (2 mm for NAcc and $4 \mathrm{~mm}$ for $\mathrm{CPu}$ ) dialysis probe was inserted through the guide cannulae and the rats were transferred to the dialysis chamber $(40 \times 34 \mathrm{~cm})$. The probes were connected to the Bioanalytical Systems syringe pump via peek tubing connected to two-channel swivel. The perfusion fluid was composed of $145 \mathrm{mM} \mathrm{NaCl}, 2.2 \mathrm{mM} \mathrm{CaCl}_{2}$, and $4 \mathrm{mM} \mathrm{KCl}$. Samples were collected and immediately injected onto an HPLC column. Twenty-four hours or 8 days after restraint, a dialysis probe was inserted through the guide cannula and the perfusion fluid started immediately $(1 \mu \mathrm{l} / \mathrm{min})$. After $1 \mathrm{~h}$, baseline samples were collected. Once the basal dopamine levels were stable, the rats received an injection of d-AMPH $(0.5 \mathrm{mg} / \mathrm{kg}$ i.p. $)$ or saline and samples were collected for $180 \mathrm{~min}$.

\section{Measurement of DA Levels in Microdialysis Samples}

The perfusate was assayed for DA by reverse-phase HPLC coupled with electrochemical detection. The mobile phase was composed of $50 \mathrm{mM} \mathrm{NaH}{ }_{2} \mathrm{PO}_{4} / 5 \mathrm{mM} \mathrm{Na}_{2} \mathrm{HPO}_{4}, 0.1 \mathrm{mM}$ EDTA-Na $\mathrm{Na}_{2}, 0.5 \mathrm{mM} n$-octyl sodium sulphate, and $12 \%$ methanol; $\mathrm{pH}$ was adjusted to 5.5 . The mobile phase was delivered at a flow of $1 \mathrm{ml} / \mathrm{min}$ (Model 582, solvent delivery model; ESA, Chelmsford, MA) through a RP 18 column $(\mathrm{C} 18,125 \times 4.6 \mathrm{~mm}, 5 \mu \mathrm{m})$. Samples were injected via a $20 \mu \mathrm{l}$ injection loop. DA was detected using coulometric detection (ESA Coulochem II). Three electrodes were used: a guard 
cell $(+350 \mathrm{mV})$, an oxidation analytical electrode $(+175 \mathrm{mV})$, and a reduction analytical electrode $(-175 \mathrm{mV})$. Peaks were recorded, and the height was measured by a computer using an ESA Chromatography Data System. These values were quantified by comparison with an external standard curve.

\section{Data Analyses}

All values from microdialysis experiments are expressed as percentage of baseline \pm SEM. The basal DA values are included in the text and expressed as fmol/20 $\mu \mathrm{l} \pm$ SEM. The average concentration of the four samples before drug injection was defined as the baseline. Data were included for analysis if the four baseline samples varied less than $15 \%$ from each other and if, within group, they did not exceed the mean value plus or minus twice the SD. All data was statistically evaluated using a two-way ANOVA for repeated measures analysis, with the following factors: treatment ( 0 or 1 restraint stress session), drug (MK-801 or saline) and time as the repeated measure (Figures 1,3-5); or treatment (0 or 1 restraint stress session), AMPH dose (d-AMPH or saline) and time as the repeated measure (Figure 2). All ANOVA were followed by a Newman-Keul's test for post-hoc comparisons. The level of significance for all procedures was $p<0.05$.

\section{Histology}

At the end of the experiments, in order to assess probe placements, rats were deeply anesthetized with choral hydrate $(400 \mathrm{mg} / \mathrm{kg}$ i.p.) and perfused transcardially with a solution of formaldehyde $(10 \% \mathrm{v} / \mathrm{v})$. The brains were stored in formaldehyde $(10 \% \mathrm{v} / \mathrm{v})$ until the time of sectioning. Following fixation, coronal sections of $60 \mu \mathrm{m}$ thicknesses were cut on a cryostat, and each section was stained with Thionin. The cannula placements were determined according to the atlas of Paxinos and Watson (1997) with a light microscope.
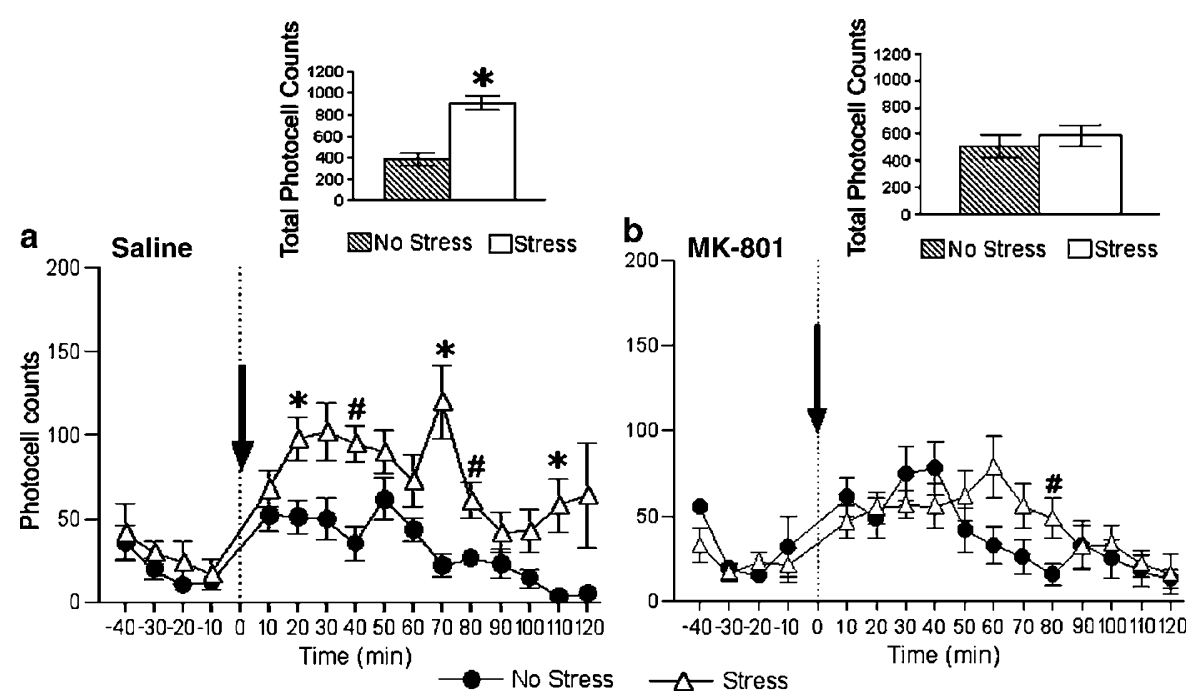

Figure I Reversal by MK-80I of the restraint stress-induced sensitization to locomotor activating effects of d-AMPH. Rats were injected with (a) saline or (b) MK-80I (0.1 mg/kg i.p.) $30 \mathrm{~min}$ before $2 \mathrm{~h}$ of restraint stress. Rats from the no-stress group after receiving drug or saline, were returned to their home cages. Twenty-four hours after, the stress-induced sensitization at locomotor response to d-AMPH was blocked in MK-80 I stress group ( $n=8-1$ I for each group). Values represent the means $( \pm$ SEM) of photocell counts over 10-min periods. $*$ indicates $p<0.005$ compared with all the remaining groups (Saline No Stress, MK-80I No Stress and MK-80 I Stress). A \# sign indicates $p<0.05$ compared with Saline No Stress group. Comparisons between groups were at the same time point by the Newman-Keuls test. Arrow indicates $0.5 \mathrm{mg} / \mathrm{kg}$ d-AMPH i.p. injection. At the top of both figures (a and b) the total photocell counts over $120 \mathrm{~min}$ were shown as means $( \pm \mathrm{SEM})$, * indicates $p<0.005$ compared with all the remaining groups.
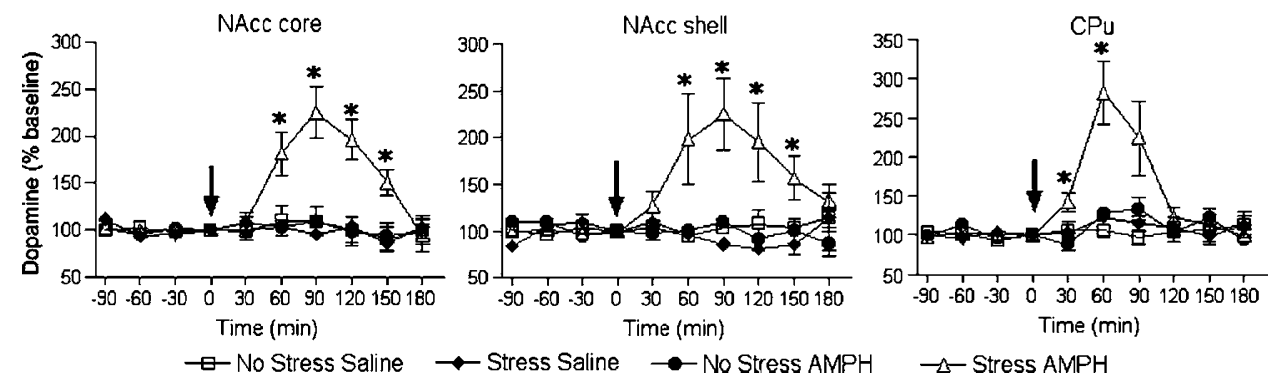

Figure 2 Twenty-four hours after a restraint stress DA release from NAcc core, NAcc shell, and CPu is enhanced following an AMPH injection. Rats were restrained for two hours or stayed in their home cages. Twenty-four hours later, DA release from NAcc core, NAcc shell, and CPu was measured following a saline or d-AMPH (0.5 mg/ $/ \mathrm{kg}$ i.p.) injection ( $n=5-8$ for each group). Values represent percentage of increase of DA release from baseline (means \pm SEM) * indicates $p<0.05$ compared with No Stress (Saline and d-AMPH), and Stress Saline. Arrow indicates a saline or d-AMPH (0.5 mg/kg i.p.) injection. Comparisons between groups were at the same time point by the Newman-Keuls test. 


\section{Experimental Design}

Rats were randomly assigned to one of four conditions defined by treatment ( 0 or 1 restraint stress session) and drug: saline ( $1 \mathrm{ml} / \mathrm{kg}$ i.p.) and MK-801 $(0.1 \mathrm{mg} / \mathrm{kg}$ i.p. $)$ or by treatment ( 0 or 1 restraint stress session) and AMPH dose: saline $(1 \mathrm{ml} / \mathrm{kg}$ i.p.) and d-AMPH $(0.5 \mathrm{mg} / \mathrm{kg}$ i.p.). Thirty minutes after MK-801 or saline administration, the 'stressed' rats were submitted to a restraint stress session, whereas the 'control' rats were returned to their home cages and left undisturbed. Twenty-four hours (Figures 1 and 3) or 8 days after (Figures 4 and 5), the animals of each group were subdivided for microdialysis and locomotor activity assays to test the effects of a challenge dose of d-AMPH $(0.5 \mathrm{mg} / \mathrm{kg}$ i.p.). Different no stress and stress groups were used to test the effect of a challenge injection of saline or d-AMPH on DA release $24 \mathrm{~h}$ after the restraint stress (Figure 2). Considering that a persistent stress-induced sensitization on DA release after d-AMPH was found only in NAcc core, the influence of MK-801 pretreatment 8 days
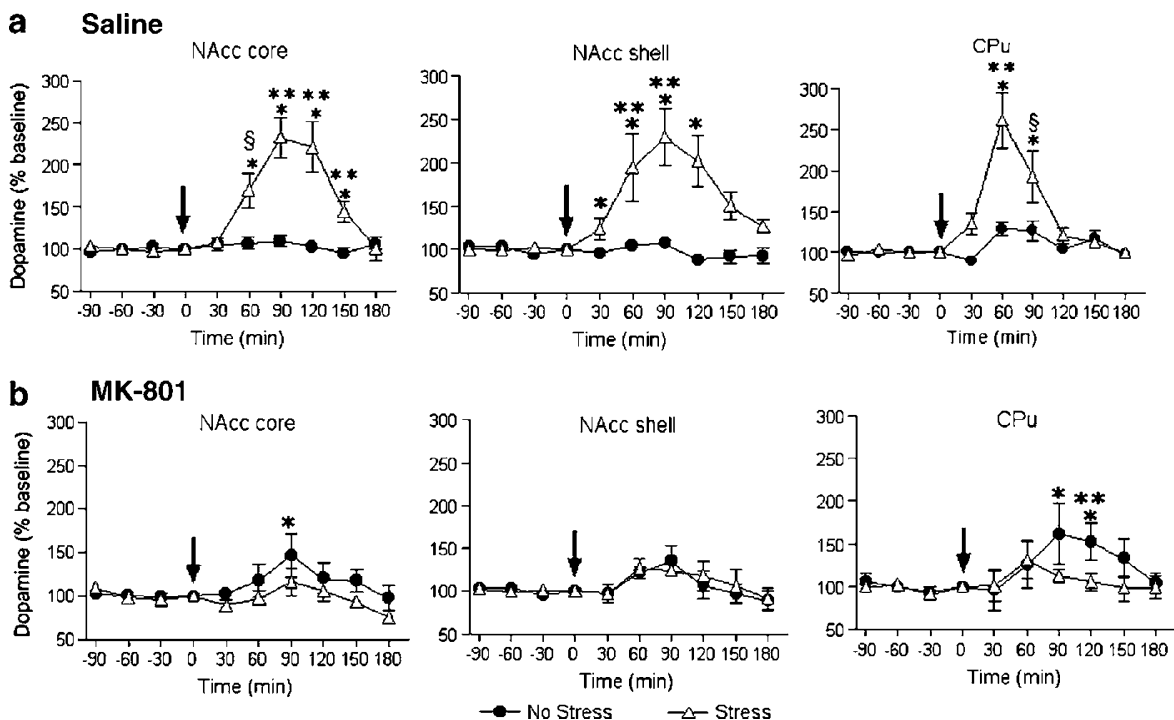

Figure 3 Reversal by MK-80 I of the restraint stress-induced sensitization to d-AMPH-induced DA release from NAcc core, NAcc shell, and CPu. Rats were under the same experimental design described in Figure I. Twenty-four hours later, the stress-induced sensitization on d-AMPH-evoked DA release from NAcc core, NAcc shell, and CPu were blocked in MK-80I Stress group ( $n=5-7$ for each group). * indicates $p<0.05$ compared with baseline DA levels. $* *$ indicates $p<0.005$ compared with the values of all the remaining groups (Saline No Stress, MK-80I No Stress and MK-80I Stress). A $\S$ sign indicates $p<0.05$ compared with Saline No Stress and MK-80 I Stress groups. Comparisons between groups were at the same time points by the NewmanKeuls test. Arrow indicates $0.5 \mathrm{mg} / \mathrm{kg}$ d-AMPH i.p. injection.

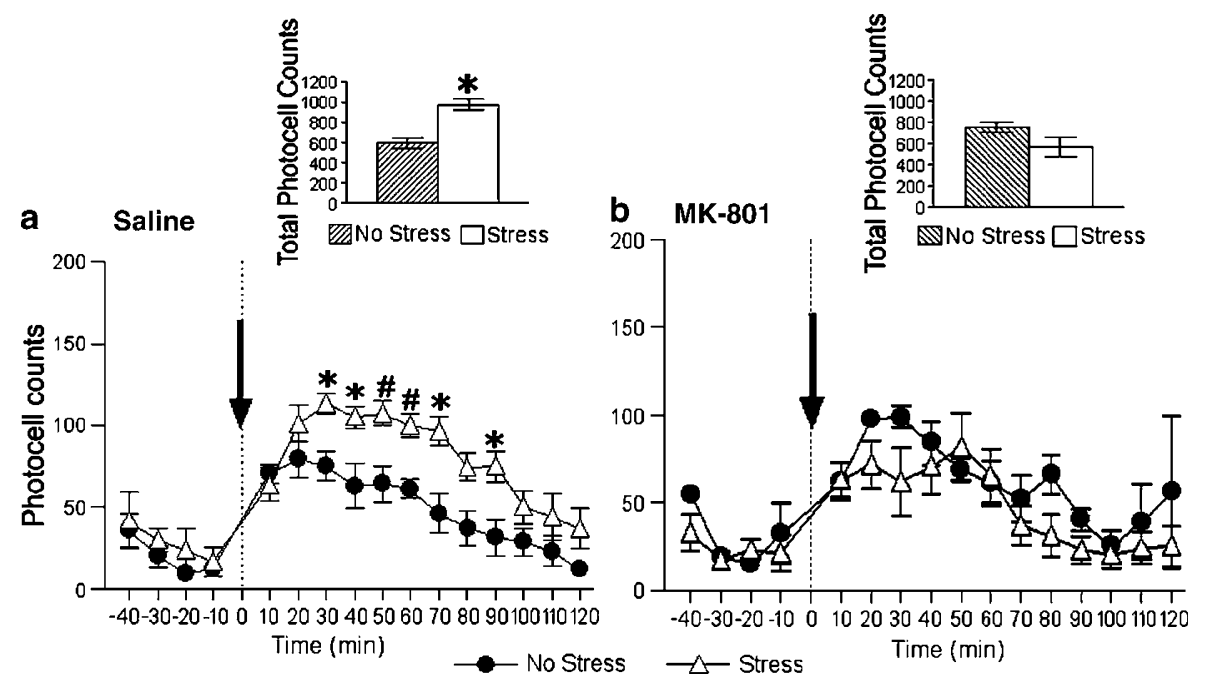

Figure 4 Reversal by MK-80 I of the restraint stress-induced sensitization to locomotor activating effects of d-AMPH administered 8 days after stress. Rats were under the same experimental design described in Figure I. Eight days after, the stress-induced sensitization at locomotor response to d-AMPH was blocked in MK-80I Stress group ( $n=6-10$ for each group). Values represent the means ( \pm SEM) of photocell counts over 10 -min periods. $*$ indicates $p<0.005$ compared with all the remaining groups. A \# sign indicates $p<0.05$ compared with Saline No Stress group. Comparisons between groups were at the same time point by the Newman-Keuls test. Arrow indicates $0.5 \mathrm{mg} / \mathrm{kg} \mathrm{d}$-AMPH i.p. injection. At the top of both figures the total photocell counts over 120 min were shown as means $( \pm S E M)$, * indicates $p<0.005$ compared with all the groups. 
after stress session on this effect was only studied in NAcc core. Each animal was used only once.

\section{RESULTS}

A total of 191 rats were used for the microdialysis experiments. The data from 156 rats passed all inclusion criteria, including measurable dopamine levels in both NAcc and $\mathrm{CPu}$, stable baseline DA levels and confirmed probes placements (Figure 6). There was no significant difference in basal dopamine levels among different experimental groups in the NAcc core, NAcc shell, or $\mathrm{CPu}$. Average basal DA levels (not corrected by recovery) were $116.4 \pm 13.3 \mathrm{fmol} / 20 \mu \mathrm{l}$ in NAcc core, $115.3 \pm 18.3 \mathrm{fmol} / 20 \mu \mathrm{l}$ in NAcc shell, and $115.7 \pm 20.3 \mathrm{fmol} / 20 \mu \mathrm{l}$ in $\mathrm{CPu}$.

\section{A Single Restraint Stress Induced an Enhanced Response to d-AMPH on Locomotor Activity and $\mathrm{DA}$ Release from NAcc Core, Shell and $\mathrm{CPu}$, Which was Prevented by a MK-801 Pretreatment}

We have previously demonstrated that the stimulation of NMDA receptors is necessary for the stress-induced enhancement to the stimulating effect of d-AMPH and morphine on locomotor activity, $24 \mathrm{~h}$ after a restraint stress session (Pacchioni et al, 2002; Capriles et al, 2002). To draw a parallel between the previous findings and the microdialysis experiments, we ran the locomotor activity assay in a different group of rats, and used a new set of activity monitors. The results (Figure 1a and b) again showed a restraint stress-induced enhanced behavioral response, which was prevented by the MK-801 pretreatment (treatment $\mathrm{F}(1,34)=16.39, \quad p<0.0005 ; \quad \operatorname{drug} \quad \mathrm{F}(1,34)=4.77$, $p<0.05$; and time $\mathrm{F}(11,374)=8.89 p<0.0001$; treatment $\times$ drug $\mathrm{F}(1,34)=6.62, \quad p<0.05 ; \quad$ and treatment $\times$ time $\mathrm{F}(11,374)=2.29, p<0.05)$. Newman-Keuls post-hoc comparisons indicated that the Saline Stress group shows significantly higher photocell counts at 20,70, and 110 min compared with MK-801 Stress and all No Stress groups. These comparisons also showed that counts at 40 and $80 \mathrm{~min}$ in the Saline Stress group were significantly higher than the Saline No Stress group. The total photocell counts over $120 \mathrm{~min}$ after d-AMPH injection (right top corner Figure 1a and b) also showed the higher response of the Saline Stress group with regard to that of the MK-801 Stress and all no-stress groups (treatment $\mathrm{F}(1,34)=15.6$, $p<0.0005$; and drug $\mathrm{F}(1,34)=4.95, p<0.05$; treatment $\times$ drug $\mathrm{F}(1,34)=6.79, \quad p<0.05)$. Newman-Keuls post-hoc comparisons indicated that the total cumulative counts in
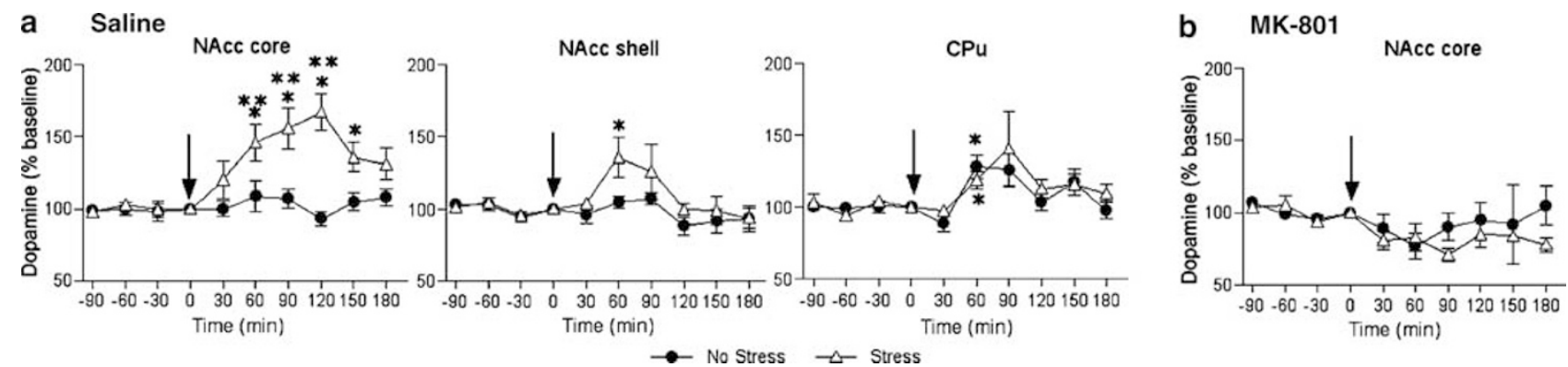

Figure 5 Reversal by MK-80 I of the restraint stress-induced sensitization to d-AMPH-induced DA release from NAcc core, 8 days after stress. Rats were under the same experimental design described in Figure I. Eight days later, the stress-induced sensitization on d-AMPH-evoked DA release from NAcc core was blocked in MK-80 I Stress group ( $n=5-7$ for each group). * indicates $p<0.05$ compared with baseline DA levels. ** indicates $p<0.005$ compared with the values of all the remaining groups. Comparisons between groups were at the same time points by the Newman-Keuls test. Arrow indicates $0.5 \mathrm{mg} / \mathrm{kg}$ d-AMPH i.p. injection.
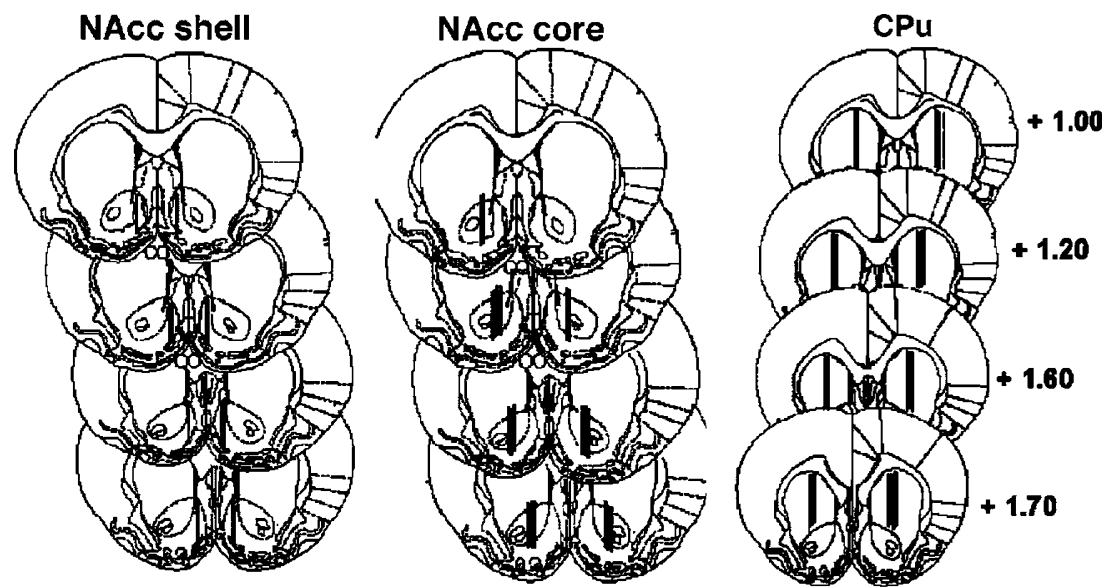

Figure 6 Schematic sections of the rat brain, adapted from the stereotaxic atlas of Paxinos and Watson (1997), showing the location of microdialysis probes in NAcc shell, NAcc core, and CPu. For details and exact coordinates, see Materials and methods. 
the Saline Stress group was significantly increased compared to those of the MK-801 Stress and all No Stress groups. It is important to mention that the irregular enhanced response observed in Saline Stress rats (significantly higher than the Saline No Stress group at 20,40,70, 80 , and 110) does not mimic the sensitized response seen in d-AMPH-exposed animals by other authors. This pattern seems to be a characteristic response to AMPH $24 \mathrm{~h}$ after the stress session, as was also shown in our previous studies (Diaz-Otañez et al, 1997; Pacchioni et al, 2002).

Restraint stress induced a higher DA release evoked by $\mathrm{d}-\mathrm{AMPH}$ in NAcc core and shell subdivisions and $\mathrm{CPu}$ compared with those observed after Saline injection (Figure 2). A two-way ANOVA applied on results in Figure 2 showed the following significant effects: for NAcc core data treatment $\times \mathrm{AMPH}$ dose $\times$ time interaction $\mathrm{F}(6,126)=8.08$, $p<0.0001$; for NAcc shell data treatment $\times$ d-AMPH dose $\times$ time interaction $\mathrm{F}(6,90)=4.51, p<0.01$, and for $C P u$ data treatment $\times$ d-AMPH dose $\times$ time interaction $\mathrm{F}(6,120)=$ 3.34, $p<0.05$. Newman-Keuls post-hoc comparisons for NAcc core and NAcc shell showed a significant increase in the percentage of basal DA output at $60,90,120$, and $150 \mathrm{~min}$ in stressed rats following an d-AMPH injection comparing to baseline levels and to values in No Stress groups (Saline and d-AMPH), and Saline Stress group. The same comparisons for $\mathrm{CPu}$ data showed a significant increase of DA release 30 and 60 min after d-AMPH. A Saline injection did not modify DA release either in No Stress or in Stress rats in any of the studied brain areas. It should be mentioned that using a low dose of d-AMPH $(0.5 \mathrm{mg} / \mathrm{kg}$ i.p.), we confirmed our previous findings on stress-induced effects obtained with a higher dose of d-AMPH. As the low dose of d-AMPH $(0.5 \mathrm{mg} / \mathrm{kg}$ i.p. $)$ was not effective in evoking DA release in no stressed rats, we injected a few rats from the No Stress group with d-AMPH ( $1 \mathrm{mg} / \mathrm{kg}$ i.p) at the end of saline challenge experiment and we measured the DA release in NAcc core $(n=4)$ and NAcc shell $(n=3)$ only for $60 \mathrm{~min}$. A clear DA increase following d-AMPH was observed in both nuclei from the no-stress group (data not shown), which once again corroborates the well-known DA-releasing effect of this drug in naive rats.

In agreement with the behavioral results, we showed in a separate set of rats that MK-801 pretreatment prevented the stress-induced enhancement in the DA release for all nuclei studied (Figure 3a and b). As saline injection has no effect in No Stress or Stress groups (Figure 2), only the challenge with $\mathrm{d}-\mathrm{AMPH}$ was tested in these studies on the influence of MK-801 on stress-induced effects. With regard to the NAcc core data (Figure $3 \mathrm{a}$ and $\mathrm{b}$ ), a two-way ANOVA for repeated measures revealed a significant drug $\times$ treatment $\times$ time interaction $\mathrm{F}(6,90)=4.59, p<0.0005$. Newman-Keuls posthoc comparisons showed that only in the Saline Stress group there was a significant increase in the percentage of basal DA output observed following 60, 90, 120, and $150 \mathrm{~min}$ of the d-AMPH challenge with regard to baseline levels. These comparisons also showed that this increase was significantly different from the values of all the remaining groups (Saline No Stress, MK-801 No Stress, and MK-801 Stress) at 90, 120, and $150 \mathrm{~min}$. For NAcc shell data, a two-way ANOVA for repeated measures performed on the data in Figure $3 a$ and $b$, revealed a significant drug $\times$ treatment $\times$ time interaction $\mathrm{F}(6,102)=2.47, p<0.05$. Newman-Keuls post-hoc comparisons indicated a significant increase in the percentage of basal DA at the $60,90,120$, and $150 \mathrm{~min}$ time points post d-AMPH challenge in the salinestressed group with regard to baseline levels, and at 90 and $120 \mathrm{~min}$ it was also different from the values of all the remaining groups.

For CPu data, a two-way ANOVA for repeated measures conducted on data depicted in Figure $3 \mathrm{a}$ and $\mathrm{b}$ revealed a significant drug $\times$ treatment interactions $\mathrm{F}(1,21)=14.65$, $p<0.001$; drug $\times$ time interaction $\mathrm{F}(6,126)=2.5, p<0.05$; and treatment $\times$ time interaction $\mathrm{F}(6,126)=2.48, p<0.05$. Newman-Keuls post-hoc comparisons showed a significant increase in the percentage of basal DA output following 60 and $90 \mathrm{~min}$ of $\mathrm{d}-\mathrm{AMPH}$ challenge in the Saline Stress group with regard to baseline levels. At $60 \mathrm{~min}$, a significant increase in the percentage of basal DA output was observed in the Saline Stress group compared with values of all the remaining groups.

The Saline No Stress group (Figure 3a) did not show an increase in DA output in response to d-AMPH in none of the nuclei studied, and the MK-801 No Stress group (Figure 3b) showed an increase in DA output from NAcc core and $\mathrm{CPu}$ compared to basal levels in response to AMPH. Both of these observations need to be addressed.

\section{The Increase in Locomotor Activity and DA Response to d-AMPH in NAcc Core Persisted 8 days after Stress and was Prevented by a MK-801 Pretreatment}

We have previously demonstrated that a single restraint session induced an enhancement of d-AMPH stimulating effect, 8 days after a restraint stress session (Diaz-Otañez et al, 1997). The present results (Figure $4 \mathrm{a}$ and b) confirmed these previous findings and demonstrated that glutamate also participates in the persistence of the stress-induced effects. Indeed, locomotor enhancement observed 8 days following a single restraint stress experience is prevented by MK-801 pretreatment (time $\mathrm{F}(11,308)=15.3 p<0.0001$; treatment $\times$ drug interaction $\mathrm{F}(1,28)=16.21, p<0.0001)$. Newman-Keuls post-hoc comparisons indicated that photocell counts at 20,30,70, and $90 \mathrm{~min}$ in Saline Stress group were significantly higher than those obtained in MK-801 stress and all no-stress groups. These comparisons also showed that counts at 50 and $60 \mathrm{~min}$ in the Saline Stress group were significantly higher than those from the Saline No Stress group. These figures also depicted the total photocell counts over $120 \mathrm{~min}$ in saline and MK-801 Stress and No Stress groups challenged with d-AMPH. A two-way ANOVA applied to the total cumulative counts over $120 \mathrm{~min}$ showed a significant treatment $\times$ drug interaction $\mathrm{F}(1,28)=16.21, p<0.0001$. Newman-Keuls post-hoc comparisons indicated that the total cumulative counts in the saline stress group was significantly increased with regard to those of the MK-801 stress and all no-stress groups. Although it is clear that MK-801 before restraint stress blocked the enhanced response to d-AMPH, it should be mentioned that MK-801 administration induced a nonsignificant trend of increasing the locomotor responding to $\mathrm{d}-\mathrm{AMPH}$ in Saline No Stress animals (see explanation of this effect in Discussion). 
Eight days after restraint (Figure $5 \mathrm{a}$ and b), only NAcc core shows an enhanced DA release after d-AMPH and this effect was blocked by MK-801 pretreatment (drug $\mathrm{F}(1,18)=29.33$, $p<0.0001$; drug $\times$ treatment $\mathrm{F}(1,18)=12.82, p<0.005$; and time $\times$ drug $\mathrm{F}(6,108)=2.9, p<0.05)$. Newman-Keuls posthoc comparisons showed that only in the saline stressed group was a significant increase in the percentage of basal DA output observed at $60,90,120$, and 150 min following the d-AMPH challenge with regard to baseline levels. These comparisons also showed that this increase was significantly different from the values of all the remaining groups (Saline No stress, MK-801 No Stress, and MK-801 Stress) at 60, 90, and $120 \mathrm{~min}$.

Figure 5a also showed the data from NAcc shell and $\mathrm{CPu}$. One-way ANOVA for repeated measures applied to the data on each area, revealed a main effect of time $\mathrm{F}(6,54)=$ 4.39, $p<0.005$ (NAcc shell); and $\mathrm{F}(6,90)=6.903, p<0.0005$ $(\mathrm{CPu})$. Newman-Keuls post-hoc comparisons showed a significant increase in the percentage of basal DA output at $60 \mathrm{~min}$ following of the $\mathrm{d}-\mathrm{AMPH}$ challenge compared to baseline levels in NAcc shell Stress group, and in $\mathrm{CPu}$ Stress and No Stress groups. However, no difference was observed among all the different groups. Also, saline nostress animals failed to show an increased DA response in the different nuclei following d-AMPH.

\section{Assessment of Cannula Placements}

Animals in which the traces of the probes were located outside the NAcc core, shell or $\mathrm{CPu}$, and animals showing excessive gliosis were discarded from the experiments. Probe placements are illustrated in Figure 6.

\section{DISCUSSION}

The current study provides a neural/neurochemical basis for the restraint stress-induced behavioral enhancement to $\mathrm{d}-\mathrm{AMPH}$ response. The principal findings are that (1) a single restraint stress exposure is a pertinent stimulus to enhance d-AMPH's stimulating effects on DA transmission in the $\mathrm{CPu}$ and the two subdivisions shell and core of the NAcc, (2) only the NAcc core shows an enhanced DA release following the longest interval between restraint stress and d-AMPH challenge (ie 1 week vs 1 day), (3) pretreatment with a non-competitive NMDA antagonist, MK-801, abrogated the restraint stress-induced d-AMPH enhancement on DA neurotransmission and locomotor activity (at both times after stress). Our results strongly suggest that NMDA receptors are involved in the stress-induced changes at the dopaminergic pathways underlying the higher response to d-AMPH. The long-term DA-enhanced response observed in the NAcc core (but not in the NAcc shell or CPu), highlights the potential relevance of the NAcc core in the long-lasting proactive stress effects on vulnerability to drug abuse.

The present results are in agreement with our previous reports showing that a single restraint stress is sufficient to induce behavioral enhancement to the stimulating and rewarding properties of d-AMPH (Diaz-Otañez et al, 1997; Capriles and Cancela, 1999). The enhancement in psychostimulants effects induced by non-pharmacological stressors has been observed by several laboratories at behavioral and neurochemical levels (Camp and Robinson, 1988; RougePont et al, 1995; Deroche et al, 1995; Kalivas and Stewart, 1991; see Lu et al, 2003). Stressors as well as drugs of abuse acutely activate the mesocorticolimbic dopaminergic system (Doherty and Gratton, 1992; Imperato et al, 1992; Di Chiara and Imperato, 1988; Pontieri et al, 1995) which is known to be involved in the stimulating and rewarding effects of opioid and psychostimulant drugs (Wise and Bozarth, 1987).

In the context of long-lasting effects of stress and drug exposure, the mesocorticolimbic system has been implicated in the development and expression of sensitization to psychostimulants (Kalivas and Stewart, 1991; Pierce and Kalivas, 1997). In agreement, the present results provide evidence of an enhancement in the d-AMPHinduced DA responsiveness in the NAcc in both core and shell subdivisions, and in the $\mathrm{CPu}, 24 \mathrm{~h}$ following a single restraint stress which parallels the behavioral enhancement in terms of locomotor activity. These observations are reminiscent of those of Vanderschuren et al (1999), who found that a single exposure to d-AMPH is sufficient to induce an increase in the electrically evoked release of $\left[\mathrm{H}^{3}\right]$ dopamine from $\mathrm{Nacc}, \mathrm{CPu}$ and cortex slices, in parallel to the development of locomotor sensitization at 3 days and 3 weeks after treatment. Notwithstanding, this latter study did not provide any evidence regarding the contribution of NAcc shell and NAcc core to AMPH sensitization. A significant finding of the present study was that the differential contribution of both subdivisions of NAcc to the hyperreactivity of dopaminergic terminals depends on the interval between the stress experience and the drug challenge. The long-term enhanced DA response to d-AMPH in NAcc core resembles that found in a model of opiate- and psychostimulant-induced sensitization (Robinson et al, 1988; Wolf et al, 1993; Paulson and Robinson, 1995; Cadoni and Di Chiara, 1999; Cadoni et al, 2000) as well as that observed in response to different psychostimulants following a chronic schedule of food restriction (Cadoni et al, 2003), while that observed in NAcc shell (ie the short lasting one) is consistent with sensitization to morphine following an inescapable shock administered $24 \mathrm{~h}$ previously (Bland et al, 2004). As contradictory evidence has been found in NAcc shell in terms of DA release in models of drug-induced sensitization, it is difficult to relate our present findings to them. For instance, while cross sensitization to d-AMPH in NAcc shell is observed following a repeated treatment with cocaine (Pierce and Kalivas, 1995) it was not found following an opiate and d-AMPH repeated treatment (Cadoni and Di Chiara, 1999; Cadoni et al, 2000). In general terms, the majority of models of drug-induced sensitization mentioned above are based on laboratory animals that have received repeated injections of psychostimulants. Most of them have reported that sensitized DA release is not seen 3-4 days later but rather emerges 1 week after the last pre-exposure injection. Our current findings indicate that restraint stress-induced shortterm DA enhancement appears faster (ie at $24 \mathrm{~h}$ ) than that observed following drugs, and in a similar way to that shown following an inescapable shock (Bland et al, 2004). Although caution should be used when comparing stressand drug-induced sensitization, we can speak of the long- 
term nature of the restraint stress-induced enhancement of DA release in NAcc core as the behavioral enhancement seen 1 week after restraint stress resembles that found 1 week or more following drugs. However, Saline Stress rats also showed a significant increase in the DA output from baseline in NAcc shell (Figure 5a). Although this increase was not significant compared to the other groups, it does suggest a trend in NAcc shell which should be considered in future studies. Restraint stress did not affect the DA response to a saline injection in any studied area, since 'no stressed' and 'stressed' animals showed no changes in DA output from basal levels (Figure 2). Therefore, the DA response observed in 'stressed' animals is necessarily d-AMPH-dependent and not due to injection stress. Furthermore, restraint stress-induced enhanced DA release in $\mathrm{CPu}$ was also shown by using a higher dose of $\mathrm{d}-\mathrm{AMPH}$ (1.5 mg/kg i.p.) (Pacchioni et al, 2002).

The enhanced behavioral response to d-AMPH after stress had different temporal patterns depending on the interval between stress exposure and drug. The irregular pattern to d-AMPH observed $24 \mathrm{~h}$ after the stress session seems to be a characteristic response at this time point, as was shown in our previous studies (Diaz-Otañez et al, 1997; Pacchioni et al, 2002), while that observed 1 week after stress had a more regular and sustained pattern. The difference in the behavioral responses to d-AMPH after stress might be related to the clearly different d-AMPHinduced DA response underlying both the short- and the long-term stress-induced effects.

It is well known that an AMPH injection increases the behavioral response and DA release in striatum (Carboni et al, 2003; Cadoni et al, 2003; Kuczenski et al, 1997; Lecca et al, 2004). However, in the current study, the temporal response to d-AMPH was not significantly different from Saline in No Stress animals. The neurochemical studies also failed to show a d-AMPH-induced DA release in the No Stress group for all nuclei studied. Two factors could help to explain the lack of behavioral and neurochemical effects after d-AMPH (0.5 mg/kg i.p.) in No Stress group: (1) rat strain: Wistar rats were used in the current study vs Sprague Dawley or Wistar Kyoto, (2) housing conditions previous to the microdialysis assay: two animals per cage in the present study $v s$ individually housed. In addition, our microdialysis conditions (collection time of $30 v s 20 \mathrm{~min}$ ) might dilute the d-AMPH's effect in terms of percentage of change of DA release from baseline.

We have also shown that a pretreatment with MK-801 blocked the restraint stress-induced locomotor and DA enhancement in the studied brain areas at both time points. In a similar way, Wolf et al (1994) found that MK-801 prevented behavioral sensitization to d-AMPH and related changes in the mesoaccumbens DA system. Thus, a link between glutamate and DA can be established in a neural circuit underlying the development of restraint stressinduced enhancement and drug-induced sensitization to psychostimulants. Notwithstanding the clear blocking effect of MK-801 in the development of stress-induced enhanced response, it should be mentioned that MK-801 induced a significant increase in DA output compared to basal levels in response to d-AMPH in the No Stress group (Figure $3 \mathrm{~b}$ ). Our behavioral results also showed a non-significant trend to increase the $\mathrm{d}-\mathrm{AMPH}$ response 8 days following one injection of MK-801 in the No Stress group. It has been reported that repeated $\mathrm{MK}-801$ treatment increases locomotor activity and can develop sensitization to its own injection (Carey et al, 1995; Segal et al, 1995; Sripada et al, 1998; Vanderschuren et al, 1997; Wolf and Khansa, 1991). However, when MK-801 is coadministered with AMPH, the development of sensitization was blocked suggesting that MK-801 itself produces sensitization through a different mechanism than AMPH (Wolf and Khansa, 1991). Furthermore, repeated $\mathrm{MK}-801$ pretreatment prevented the social defeat-induced behavioral sensitization to AMPH (Yap et al, 2005). The relationship between the stimulant effect and DA release in NAcc is not clear, some researchers found an increase in DA release after MK-801 (Mathe et al, 1999; Yan et al, 1997) but others did not (Druhan et al, 1996). Regarding the long-term effect of a single MK-801, O'Neill and Sanger (1999) showed that a single MK-801 injection can modify the behavioral response to MK-801 4, 7, and 14 days after, indicating that a single injection of MK-801 produced long-term modifications. In brief, MK- 801 alone might modify the behavior and the DA response inducing long-term effects. However, when it is coadministered with drugs or stress it prevents their long-terms effects, suggesting that different mechanisms are involved.

There are recent studies focusing on the idea that common mechanisms between drugs and stress underlie their effects at excitatory mesocorticolimbic synapses. Saal et al (2003) have provided evidence that either acute administration of drugs of abuse (AMPH, cocaine, alcohol, nicotine, morphine) or stress (cold water swimming) induces similar effects at excitatory synapses on midbrain DA neurons, as measured by electrophysiological in vitro experiments. Specifically, an involvement of NMDA receptors has been shown in the enhancement of strength at excitatory synapses on midbrain DA neurons. Furthermore, Ungless et al (2003), have found that a key hormone in the stress response, corticotrophin-releasing factor (CRF), potentiates the NMDA receptor component of glutamatergic synaptic currents onto ventral tegmental area (VTA) DA neurons. Although it is difficult to see the relevance of the in vitro data outlined above, it has been recently shown that CRF has an important role in stress-induced cocaine relapse. In studies on footshock-induced cocaine relapse, CRF released in VTA caused a glutamate increase, which drove the cocaine seeking behavior. This CRF release in VTA after footshock is also observed in naive animals, but the glutamate increases only happen in cocaine experienced rats (Wang et al, 2005). It has also been shown that both repeated administration of cocaine or morphine, as well as repeated restraint stress, increased levels of the $\alpha$-amino3-hydroxy-5-methyl-4-isoxazole propionic acid (AMPA) receptor subunit GluR1 in the VTA (as well as the NMDA receptor subunit NR1) (Fitzgerald et al, 1996). However, this idea of a common mechanism between stress and drugs is challenged by other pharmacological and neuroanatomical studies suggesting that different neuronal systems are involved in drug priming- and footshock stress-induced relapse (see Shaham et al, 2003).

Our present findings provide an interesting behavioral/ neural/neurochemical perspective into the stress-induced enhanced d-AMPH response. Although there is not always 
a strict temporal correlation between presynaptic adaptations on DA systems and behavioral sensitization to psychostimulants (see Di Chiara, 1995), it is worth noting that our observations show a temporal parallel between the restraint stress-induced enhanced response to drugs on DA release in NAcc core and on locomotor activity. In spite of this, it remains likely that DA in NAcc shell and CPu may also be involved in the short-term effects. The distinct pattern of NAcc core and NAcc shell output targets, with the core projections to pallidal structures and the shell, in addition, projecting to more limbic domains (Zahm and Heimer, 1990), suggests that the two regions may mediate different aspects of the same behavioral process. We could speculate that our present findings of DAenhanced release to d-AMPH can occur as a result of restraint stress effects on excitatory synapses on the midbrain DA neurons, rendering neurons more vulnerable to a subsequent challenge with the drug. Previously described results are consistent with this hypothesis, with CRF potentiating NMDA-mediated transmission in DA neurons on VTA slices (Ungless et al, 2003), and controlling glutamate and DA release in VTA during stress-induced cocaine relapse (Wang et al, 2005). Another way in which stress could induce changes is through the glutamatergic innervation of the NAcc shell and NAcc core and $\mathrm{CPu}$, arising from structures such as the hippocampus via the subiculum, the amygdala, and the prefrontal cortex (Sesack et al, 1989; Christie et al, 1987). Wheeler et al (1995) demonstrated that MK-801 in the striatum was able to block the tail-pinch induced increase in DA in the striatum. Glutamatergic agonists applied directly to the NAcc cause release, whereas antagonists inhibit DA release (Youngren et al, 1993; Svensson et al, 1994), although more complex interactions are involved (Feenstra et al, 1998; Taber et al, 1996). More studies need to be done to determine the glutamate circuit involved in our model.

The phenomenon of behavioral sensitization has been proposed to be an adaptive process in addiction to psychostimulants and other drugs of abuse (Robinson and Berridge, 1993). This sensitization process, which shares many of the characteristics of other forms of neuronal plasticity, has been associated with either the early stages or relapse in the cycle of addiction (Robinson and Berridge, 2000; Vezina et al, 2002). Based on data on crosssensitization of locomotor activity between drug and stressors (see Kalivas and Stewart, 1991), it has also been suggested that sensitization of the stimulant effects of drugs may be of relevance to the understanding of relapse induced by stressors (see Piazza and LeMoal, 1998; Robinson and Berridge, 1993; Shaham and Stewart, 1995). Our present study provides new evidence that the neurobiological mechanisms underlying stress-induced enhanced stimulating responses resemble those observed following drugs, including involvement of NMDA receptor stimulation and augmented DA release.

\section{ACKNOWLEDGEMENTS}

This work was supported by grants from Agencia Córdoba Ciencia, SECyT, CONICET, CAEN-International Society of Neurochemistry Award and Action de cooperation scienti- fique Ecos-sud A01S03. We are grateful to Estela Salde for her laboratory technical assistance, and Paul David Hobson, $\mathrm{PhD}$ for English technical assistance.

\section{REFERENCES}

Bland ST, Twining C, Schmidt MJ, Der-Avakian A, Watkins LR, Maier SF (2004). Stress potentiation of morphine-induced dopamine efflux in the nucleus accumbens shell is dependent upon stressor uncontrollability and is mediated by the dorsal raphe nucleus. Neuroscience 126: 705-715.

Cadoni C, Di Chiara G (1999). Reciprocal changes in dopamine responsiveness in the nucleus accumbens shell and core and in the dorsal caudate-putamen in rats sensitized to morphine. Neuroscience 90: 447-455.

Cadoni C, Solinas M, Di Chiara G (2000). Psychostimulant sensitization: differential changes in accumbal shell and core dopamine. Eur J Pharmacol 388: 69-76.

Cadoni C, Solinas M, Valentini V, Di Chiara G (2003). Selective psychostimulant sensitization by food restriction: differential changes in accumbens shell and core dopamine. Eur J Neurosci 18: 2326-2334.

Cador M, Bjijou Y, Cailhol S, Stinus L (1999). D-amphetamineinduced behavioral sensitization: implication of a glutamatergic medial prefrontal cortex-ventral tegmental area innervation. Neuroscience 94: 705-721.

Camp DM, Robinson TE (1988). Susceptibility to sensitization. II. The influence of gonadal hormones on enduring changes in brain monoamines and behavior produced by the repeated administration of $\mathrm{D}$-amphetamine or restraint stress. Behav Brain Res 30: 69-88.

Capriles N, Cancela LM (1999). Effect of acute and chronic restraint stress on amphetamine-associated place preference: involvement of dopamine D1 and D2 receptors. Eur J Pharmacol 386: 127-134.

Capriles N, Pacchioni AM, Cancela LM (2002). Influence of acute or repeated restraint stress on morphine-induced locomotion: involvement of dopamine, opioid and glutamate receptors. Behav Brain Res 134: 229-238.

Carboni E, Silvagni A, Valentini V, Di Chiara G (2003). Effect of amphetamine, cocaine and depolarization by high potassium on extracellular dopamine in the nucleus accumbens shell of SHR rats. An in vivo microdyalisis study. Neurosci Biobehav Rev 27: 653-659.

Carey RJ, Dai H, Krost M, Huston JP (1995). The NMDA receptor and cocaine: evidence that MK-801 can induce behavioral sensitization effects. Pharmacol Biochem Behav 51: 901-908.

Christie MJ, Summers RJ, Stepheson JA, Cook CJ, Beart PM (1987). Excitatory aminoacid projections to the nucleus accumbens septi in the rat: retrograde transport study utilizing $\mathrm{D}\left[{ }^{3} \mathrm{H}\right]$ aspartate and $\left[{ }^{3} \mathrm{H}\right] \mathrm{GABA}$. Neuroscience 22: 425-439.

Deroche V, Marinelli M, Maccari S, Le Moal M, Simon H, Piazza PV (1995). Stress-induced sensitization and glucocorticoids. I. Sensitization of dopamine-dependent locomotor effects of amphetamine and morphine depends on stress-induced corticosterone secretion. J Neurosci 15: 7181-7188.

Di Chiara G (1995). The role of dopamine in drug abuse from the perspective of its role in motivation. Drug Alcohol Depend 38: 95-137.

Di Chiara G, Bassareo V, Fenu S, De Luca MA, Spina L, Cadoni C et al (2004). Dopamine and drug addiction: the nucleus accumbens shell connection. Neuropharmacology 47: 227-241.

Di Chiara G, Imperato A (1988). Drugs abused by humans preferentially increase synaptic dopamine concentrations in the mesolimbic system of freely moving rats. Proc Natl Acad Sci USA 85: $5274-5278$

Diaz-Otañez CS, Capriles N, Cancela LM (1997). D1 and D2 dopamine receptors are involved in the restraint stress induced 
sensitization to the psychostimulant effects of amphetamine. Pharmcol Biochem Behav 58: 9-14.

Doherty MD, Gratton A (1992). High-speed chronoamperometric measurements of mesolimbic and nigrostriatal dopamine release associated with repeated daily stress. Brain Res 586: 295-302.

Druhan JP, Rajabi H, Stewart J (1996). MK-801 increases locomotor activity without elevating extracellular dopamine levels in the nucleus accumbens. Synapse 24: 135-146.

Feenstra MG, Botterblom MH, van Uum JF (1998). Local activation of metabotropic glutamate receptors inhibits the handlinginduced increased release of dopamine in the nucleus accumbens but not that of dopamine or noradrenaline in the prefrontal cortex: comparison with inhibition of ionotropic receptors. J Neurochem 70: 1104-1113.

Fitzgerald LW, Ortiz J, Hamedani AG, Nestler EJ (1996). Drugs of abuse and stress increase the expression of GluR1 and NMDAR1 glutamate receptor subunits in the rat ventral tegmental area: common adaptations among cross-sensitization agents. J Neurosci 16: 274-282.

Imperato A, Angelucci L, Casolini P, Zocchi A, Puglisi-Allegra S (1992). Repeated stressful experiences differently affect limbic dopamine release during and following stress. Brain Res 577: 194-199.

Imperato A, Cabib S, Puglisi-Allegra S (1993). Repeated stressfull experiences differently affect the time-dependent responses of mesolimbic dopamine system to the stressor. Brain Res 601: 333-336.

Kalivas PW, Duffy P (1995). Selective activation of dopamine transmission in the shell of the nucleus accumbens by stress. Brain Res 675: 325-328.

Kalivas PW, Stewart J (1991). Dopamine transmission in the initiation and expression of drug- and stress-induced sensitization of motor activity. Brain Res Rev 16: 223-244.

Kuczenski R, Segal DS, Todd PK (1997). Behavioral sensitization and extracellular dopamine responses to amphetamine after various treatments. Psychopharmacology 134: 221-229.

Lecca D, Piras G, Driscoll P, Giorgi O, Corda MG (2004). A differential activation of dopamine output in the shell and core of the nucleus accumbens is associated with the motor responses to addictive drugs: a brain dialysis study in Roman high- and low-avoidance rats. Neuropharmacology 46: 688-699.

Lu L, Shepard JD, Hall DS, Shaham Y (2003). Effect of environmental stressors on opiate and psychostimulant reinforcement, reinstatement and discrimination in rats: a review. Neurosci Biobehav Rev 27: 457-491.

Mathe JM, Nomikos GG, Blakeman KH, Svensson TH (1999). Differential actions of dizocilpine (MK-801) on the mesolimbic and mesocortical dopamine systems: role of neuronal activity. Neuropharmacology 38: 121-128.

O'Doherty F (1991). Is drug use a response to stress? Drug Alcohol Depend 29: 97-106.

O'Neill MF, Sanger GJ (1999). A single pretreatment with MK-801 or cocaine enhances their locomotor stimulant effects in rats. Brain Res 834: 103-111.

Pacchioni AM, Gioino G, Assis A, Cancela LM (2002). A single exposure to restraint stress induces behavioral and neurochemical sensitization to stimulating effects of amphetamine: involvement of NMDA receptors. Annals NY Acad Sci 965: 233-246.

Paulson PE, Robinson TE (1995). Amphetamine-induced time dependent sensitization of dopamine neurotransmission in the dorsal and ventral striatum: a microdialysis study in behaving rats. Synapse 19: 56-65.

Paxinos G, Watson C (1997). The Rat Brain in Stereotaxic Coordinates, 3rd edn. Academic Press: New York.

Pennartz CMA, Groenewegen HJ, Lopes da Silva FH (1994). The nucleus accumbens as a complex of functionally distinct neuronal ensembles: an integration of behavioural, electrophysiological and anatomical data. Prog Neurobiol 42: 719-761.

Piazza PV, LeMoal M (1998). The role of stress in drug selfadministration. Trends Pharmacol Sci 19: 67-74.

Pierce RC, Kalivas PW (1995). Amphetamine produces sensitized increases in locomotion and extracellular dopamine preferentially in the nucleus accumbens shell of rats administered repeated cocaine. J Pharmacol Exp Ther 275: 1019-1029.

Pierce RC, Kalivas PW (1997). A circuitry model of the expression of behavioral sensitization to amphetamine-like psychostimulants. Brain Res Rev 25: 192-216.

Pontieri FE, Tanda G, Di Chiara G (1995). Intravenous cocaine, morphine, and amphetamine preferentially increase extracellular dopamine in the 'shell' as compared with the 'core' of the rat nucleus accumbens. Proc Natl Acad Sci USA 92: 12304-12308.

Robinson TE, Berridge KC (1993). The neural basis of drug craving: an incentive-sensitization theory of addiction. Brain Res Rev 18: 247-291.

Robinson TE, Berridge KC (2000). The psychology and neurobiology of addiction: an incentive-sensitization view. Addiction 95(Suppl 2): S91-S117.

Robinson TE, Jurson PhA, Bennett JA, Bentgen KM (1988). Persistent sensitization of dopamine neurotransmission in ventral striatum (nucleus accumbens) produced by prior experience with (+)-amphetamine: a microdialysis study in freely moving rats. Brain Res 462: 211-222.

Rouge-Pont F, Marinelli M, Le Moal M, Simon H, Piazza PV (1995). Stress-induced sensitization and glucocorticoids. II. Sensitization of the increase in extracellular dopamine induced by cocaine depends on stress-induced corticosterone secretion. J Neurosci 15: 7189-7195.

Saal D, Dong Y, Bonci A, Malenka RC (2003). Drugs of abuse and stress trigger a common report synaptic adaptation in dopamine neurons. Neuron 37: 577-582.

Segal DS, Kuczenski R, Florin SM (1995). Does dizocilpine (MK-801) selectively block the enhanced responsiveness to repeated amphetamine administration? Behav Neurosci 109: 532-546.

Sesack SR, Deutch AY, Roth RH, Bunney BS (1989). Topographical organization of the efferent projections of the medial pre-frontal cortex in the rat: an anterograde tract-tracing study with phaseolus vulgaris leucoagglutinin. J Comp Neurol 290: 213-242.

Shaham Y, Shalev U, Lu L, de Wit H, Stewart J (2003). The reinstatement model of drug relapse: history, methodology and major findings. Psychopharmacology (Berlin) 168: 3-20.

Shaham Y, Stewart J (1995). Effects on restraint stress and intraventral tegmental area injections of morphine and methyl naltrexone on the discriminative stimulus effects of heroin in the rat. Pharmacol Biochem Behav 51: 334-341.

Sripada S, Gaytan O, Al-rahim S, Swann A, Dafny N (1998). Doserelated effects of MK-801 on acute and chronic methylphenidate administration. Brain Res 814: 78-85.

Svensson L, Zhang J, Johannessen K, Engel JA (1994). Effect of local infusion of glutamate analogues into the nucleus accumbens of rats: an electrochemical and behavioural study. Brain Res 643: 155-161.

Taber MT, Baker GB, Fibiger HC (1996). Glutamate receptor agonists decrease extracellular dopamine in the rat nucleus accumbens in vivo. Synapse 24: 165-172.

Ungless MA, Singh V, Crowder TL, Yaka R, Ron D, Bonci A (2003). Corticotrophin-releasing factor requires $\mathrm{CRF}$ binding protein to potentiate NMDA receptors via CRF receptor 2 in dopamine neurons. Neuron 39: 401-407.

Vanderschuren LJ, Schmidt ED, De Vries TJ, Van Moorsel CA, Tilders FJ, Schoffelmeer AN (1999). A single exposure to amphetamine is sufficient to induce long-term behavioral, neuroendocrine, and neurochemical sensitization in rats. J Neurosci 19: 9579-9586. 
Vanderschuren LJ, Schoffelmeer AN, De Vries TJ (1997). Does dizocilpine (MK-801) inhibit the development of morphineinduced behavioural sensitization in rats? Life Sci 61: PL427-PL433.

Vezina P, Lorrain DS, Arnold GM, Austin JD, Suto N (2002). Sensitization of midbrain dopamine neuron reactivity promotes the pursuit of amphetamine. J Neurosci 22: 4654-4662.

Wang B, Shaham Y, Zitzman D, Azari S, Wise RA, You ZB (2005). Cocaine experience establishes control of midbrain glutamate and dopamine by corticotropin-releasing factor: a role in stressinduced relapse to drug seeking. J Neurosci 25: 5389-5396.

Wheeler D, Boutelle MG, Fillenz M (1995). The role of $N$-methyl-Daspartate receptors in the regulation of physiologically released dopamine. Neuroscience 65: 767-774.

Wise RA, Bozarth MA (1987). A psychomotor stimulant theory of addiction. Psychobiol Rev 94: 469-492.

Wolf ME (1998). The role of excitatory amino acids in behavioral sensitization to psychomotor stimulants. Progr Neurobiol 54: 679-720.

Wolf ME, Khansa MR (1991). Repeated administration of MK-801 produces sensitization to its own locomotor stimulant effects but blocks sensitization to amphetamine. Brain Res 562: 164-168.
Wolf ME, White FJ, Hu XT (1994). MK-801 prevents alterations in the mesoaccumbens dopamine system associated with behavioral sensitization to amphetamine. J Neurosci 14(3 Part 2): 1735-1745.

Wolf ME, White FJ, Nassar R, Brooderson RJ, Khansa MR (1993). Differential development of autoreceptor subsensitivity and enhanced dopamine release during amphetamine sensitization. J Pharmacol Exp Ther 264: 249-255.

Yan QS, Reith ME, Jobe PC, Dailey JW (1997). Dizocilpine (MK-801) increases not only dopamine but also serotonin and norepinephrine transmissions in the nucleus accumbens as measured by microdialysis in freely moving rats. Brain Res 765 : 149-158.

Yap JJ, Covington III HE, Gale MC, Datta R, Miczek KA (2005). Behavioral sensitization due to social defeat stress in mice: antagonism at mGluR5 and NMDA receptors. Psychopharmacology (Berlin) 179: 230-239.

Youngren KD, Daly DA, Moghaddam B (1993). Distinct actions of endogenous excitatory amino acids on the outflow of dopamine in the nucleus accumbens. J Pharmacol Exp Ther 264: 289-293.

Zahm DS, Heimer L (1990). Two transpallidal pathways originating in the rat nucleus accumbens. J Comp Neurol 302: 437-446. 